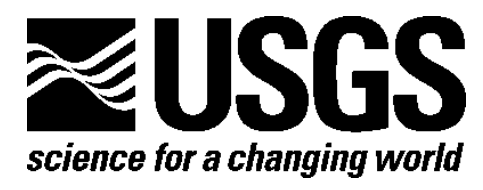

Prepared in cooperation with the Geological Society of America

\title{
Database of the Geologic Map of North America- Adapted from the Map by J.C. Reed, Jr. and others (2005)
}

By Christopher P. Garrity and David R. Soller

Data Series 424

U.S. Department of the Interior

U.S. Geological Survey 


\section{U.S. Department of the Interior \\ KEN SALAZAR, Secretary}

\section{U.S. Geological Survey \\ Suzette M. Kimball, Acting Director}

U.S. Geological Survey, Reston, Virginia: 2009

For product and ordering information:

World Wide Web: http://www.usgs.gov/pubprod

Telephone: 1-888-ASK-USGS

For more information on the USGS-the Federal source for science about the Earth,

its natural and living resources, natural hazards, and the environment:

World Wide Web: http://www.usgs.gov

Telephone: 1-888-ASK-USGS

Suggested citation:

Garrity, C.P., and Soller, D.R., 2009, Database of the Geologic Map of North America; adapted from the map by J.C. Reed, Jr. and others (2005): U.S. Geological Survey Data Series 424, http://pubs.usgs.gov/ds/424/.

Any use of trade, product, or firm names is for descriptive purposes only and does not imply endorsement by the U.S. Government. 


\section{Contents}

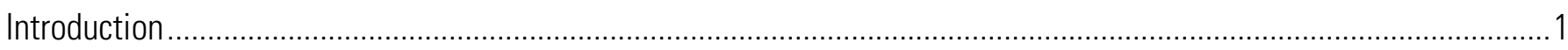

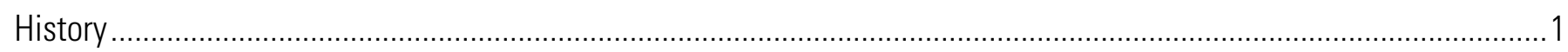

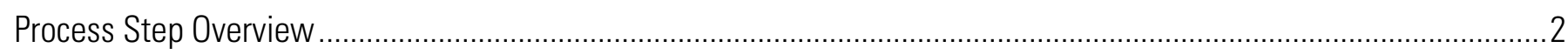

Source Map Registration Errors ..........................................................................................................................

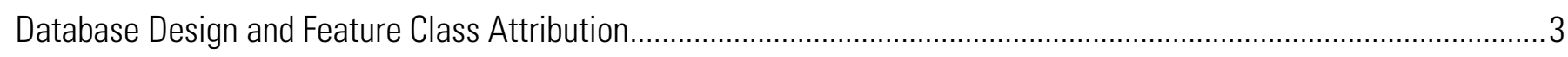

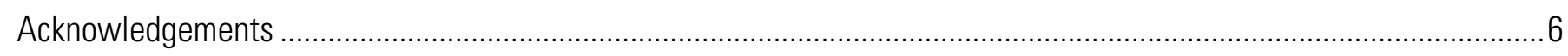

References Cited

\section{Figures}

1. Simplified GMNA database schema showing hierarchy of feature datasets, feature classes and subtypes.

4 


\title{
Database of the Geologic Map of North America- Adapted from the Map by J.C. Reed, Jr. and others (2005)
}

\author{
By Christopher P. Garrity and David R. Soller
}

\section{Introduction}

The Geological Society of America's (GSA) Geologic Map of North America (Reed and others, 2005a; 1:5,000,000) shows the geology of a significantly large area of the Earth, centered on North and Central America and including the submarine geology of parts of the Atlantic and Pacific Oceans. This map is now converted to a Geographic Information System (GIS) database that contains all geologic and base-map information shown on the two printed map sheets and the accompanying explanation sheet. We anticipate this map database will be revised at some unspecified time in the future, likely through the actions of a steering committee managed by the GSA and staffed by scientists from agencies including those responsible for the original map compilation.

Regarding the use of this product, as noted by the map’s compilers:

"The Geologic Map of North America is an essential educational tool for teaching the geology of North America to university students and for the continuing education of professional geologists in North America and elsewhere. In addition, simplified maps derived from the Geologic Map of North America are useful for enlightening younger students and the general public about the geology of the continent."

With publication of this database, the preparation of any type of simplified map is made significantly easier. More important perhaps, the database provides a more accessible means to explore the map information and to compare and analyze it in conjunction with other types of information (for example, land use, soils, biology) to better understand the complex interrelations among factors that affect Earth resources, hazards, ecosystems, and climate.

\section{History}

In 1980, when plans for the Geologic Map of North America (GMNA) were being made, the notion of geologic map databases was in its infancy. At that time, and for many years thereafter, few geologists were familiar with the design and use of databases to manage geologic map information. And so, of course, the GMNA was designed strictly as a cartographic, printed product. In 1998, the Geological Society of America (GSA) and the U.S. Geological Survey’s (USGS) National Geologic Map Database project (NGMDB) agreed to cost-share the preparation of digital files for this map. The plan was to digitize the hand-drawn, author-prepared geologic compilations for the four compiled map quadrants, in order to provide digital data for two purposes: (1) to enable GSA to print the map and (2) to permit the NGMDB to develop a database for this map (Soller, 2005). From 1998 to 2004, GSA and USGS co-funded the map digitization and the preparation of the map layout in Adobe Illustrator. The map was printed in early 2005 (Reed and others, 2005a, 2005b). 
Soon thereafter, a preliminary agreement was reached with the map publisher (GSA) and agencies responsible for the map compilation (USGS, Geological Survey of Canada, and Woods Hole Oceanographic Institute) for the NGMDB to prepare and publish the map database. In late 2005, the NGMDB began to design a Geographic Information System (GIS) database for the GMNA. The design was intended to capture all information on the printed map and, to some extent, to anticipate future requirements for content and database use as the database evolves from its origins in the printed map. In mid-2006, a GIS prototype of the GMNA (Garrity and Soller, 2006) was provided to the above-named organizations to initiate discussion and decisions on how the map database would be designed, managed, and served to the public and cooperators. These discussions were successfully concluded, and construction of the database began in 2007.

Conversion of the map to database occurred in 2007 - 2008; the processing steps are described below and summarized elsewhere (Garrity and Soller, in press). This first version (1.0) of the database contains the information shown on the printed map and serves as the fundamental entity from which products of the map can then be derived; those products may be interpretive, or they may be future editions of the map. To produce any future editions of the map, the database will incorporate all map revisions that are necessitated by detection of compilation errors and by new regional mapping and interpretations. Further, the geologic unit descriptions shown on the printed map can be supplemented in the database by more richly attributed information derived from the many sources that were used to compile the map. This capability to revise the printed map and to include additional descriptive information for map units is one of the primary reasons for building the database; the other reason is, of course, the analytical capabilities made possible by providing the map in a digital, GIS-compatible format.

With publication of this GMNA database, comparisons to recent compilations of similar regional scope and map scale are now feasible, and desirable. We anticipate, for example, a comparison of the GMNA's geology and data structure to the International Geological Map of Europe (Asch, 2003) to identify and, perhaps, address scientific issues but principally to attain database compatibility so these two maps can be analyzed and used together.

The creation of this database and its enhancement to include new mapping and more richly attributed information is a daunting task that will require a significant amount of time and effort. Recognizing that a group of dedicated and knowledgeable scientists is essential to make this database useful and to keep its content up to date, it is suggested that GSA develop a consortium of geological agencies to determine the future modifications and additions to this database.

\section{Process Step Overview}

Adobe Illustrator files containing the linework used for the hard-copy production of the Geologic Map of North America (GMNA) were obtained from USGS cartographers in Reston, VA. The two (northern and southern) Illustrator source files were massive, each containing more than 1,500 layers. Files were analyzed to determine if direct import from Adobe Illustrator to ArcGIS (via software like MaPublisher) would be the most efficient method of file conversion. When examined at scales far more detailed than that of the printed map, many areas were found to have problems in topological relationships. Common topological problems in these areas included polygons that overlapped or had gaps between them, overlying line layers (for example, contacts, faults), which were not coincident with polygon boundaries, and line features 
that self-overlapped. Although these problems were irrelevant to preparation of the hard-copy map, they were unsuitable for feature class generation.

To minimize topological errors (estimated in the hundreds of thousands), features were created via a combination of direct export from Illustrator and raster auto-vectorization. Layers containing linework coincident with geologic unit boundaries were batch exported from Illustrator with the exception of the geologic contacts layer. The geologic contact layer was exported as a series of high-resolution monochrome tiles. Raster tiles exported from Adobe Illustrator were georeferenced to local geographic coordinate positions using control points in the DNAG projection (Snyder, 1987). Images were auto-vectorized using ArcScan. Gaps and overlaps between tiles were rectified via raster painting tools. To create a topologically clean layer, topology rules were set in ArcMap and line dangles in the newly vectorized layer were snapped to the nearest unit-bordering line features.

Geologic unit layers were batch exported from the source Illustrator files and used as overlays for attributing the newly created polygon feature class. Through spatial querying, polygons in the unattributed layer that had their center within a specific overlay layer were attributed based on the overlay's geologic unit abbreviation. Remaining attribution for all other fields was completed quickly through VBA field calculator scripting based on the populated unit abbreviation field. Feature class symbolization was created to closely resemble the printed version of the GMNA. Finally, feature class symbology was exported to layer and style files.

\section{Source Map Registration Errors}

Unsystematic registration errors at latitude-longitude intersections were observed throughout the published version of the GMNA when overlain by computer generated graticules, particularly near the polar regions of the map. The amount of offset varied throughout the map, with a maximum offset estimated at about $4 \mathrm{~km}$ in certain high latitude areas. It is likely that offset was introduced in the numerous iterations (and numerous technological changes in cartographic production) of the GMNA over its twenty-year history of compilation. Some registration errors also may be caused by fundamental differences between the computer-generated graticule and the conventionally prepared GMNA base map upon which the geology was compiled.

\section{Database Design and Feature Class Attribution}

The file geodatabase was organized in a manner similar to that of the Explanation of Map Units from the Geologic Map of North America (Reed and others, 2005a). In the geodatabase, approximately 30 feature classes are grouped into the following feature datasets: Geologic_unit_features, Miscellaneous_geologic_features, Special_submarine_features, and Base_map_features (fig. 1). The Geologic_unit_feature dataset contains the data that participate in topological relationships that make up the geometry of the Geologic_units feature class. The remaining geologic features are contained in the Miscellaneous_geologic_features dataset. The Special_submarine_features dataset contains the features shown in the Special Submarine Features section of the Explanation of Map Units, with the exception of the bathymetry. Bathymetry and other base map information are contained in the Base_map_features dataset. 


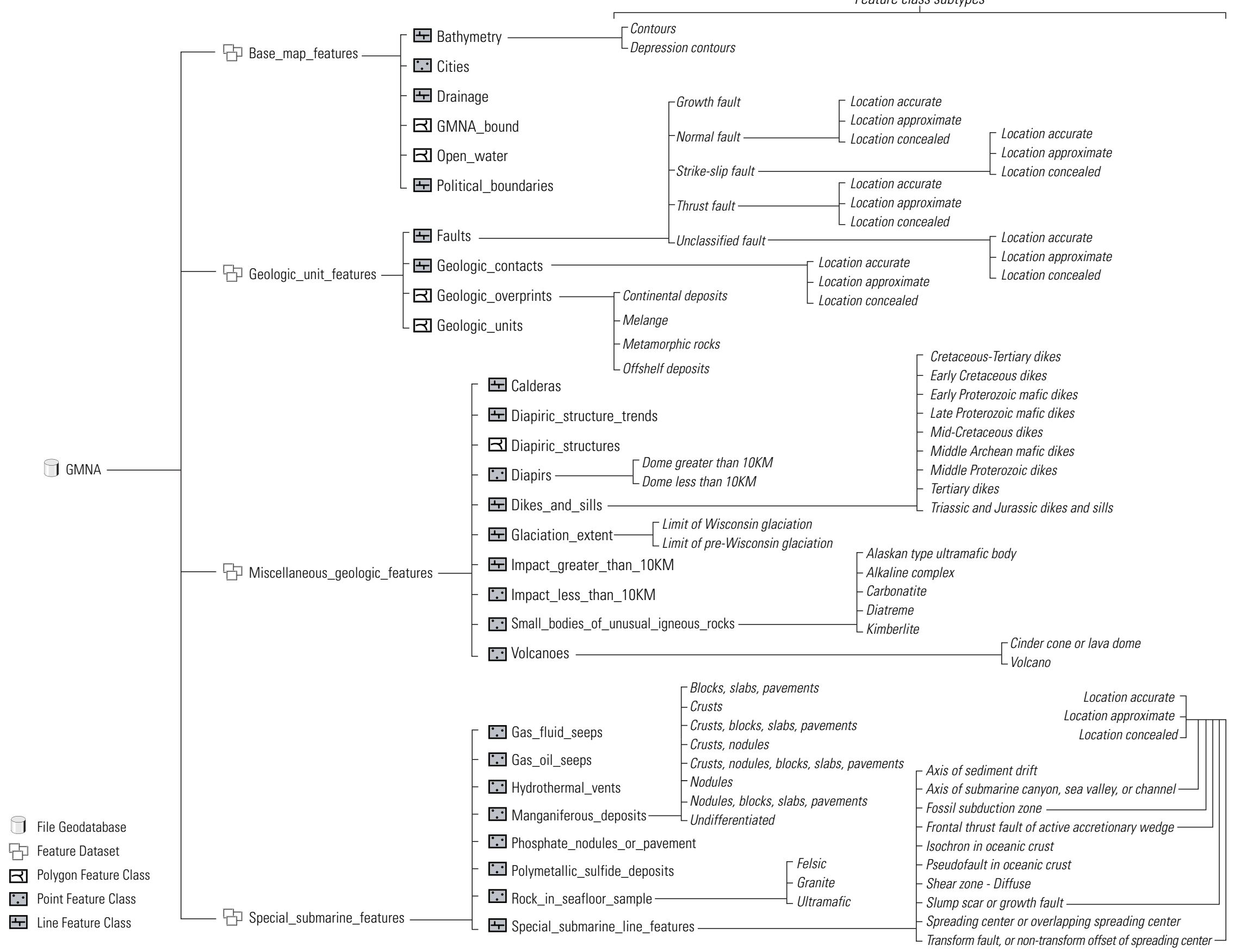

Figure 1. Simplified GMNA database schema showing hierarchy of feature datasets, feature classes and subtypes 
Many of the feature classes in the GMNA database contain subtypes. The use of subtypes ensured data consistency during the editing stages of the project. New feature classes were created and assigned subtype codes before attribution. Once created, only the subtype codes became legal attribute values. Default subtype values were also set to maximize efficiency of data entry. Generally, feature class subtypes were used when varying levels of confidence existed (for example, geologic contact certain, geologic contact inferred) or where higher order feature classes had multiple geologic classifications (Volcano - Cinder cone, Volcano - lava dome, etc.). For simplicity, all feature class subtypes were coded from the attribute field (subtype field) "TYPE”. Subtype codes are stored as short integers with corresponding feature descriptions in alphabetical order.

Detailed attribute definitions can be found in the formal metadata accompanying the database. Attribute fields in feature classes vary in number, with the most extensive attribute table belonging to the Geologic_units feature class. In this feature class, the geologic unit abbreviation attribute (UNIT_ABBREV) serves as the map unit label. The abbreviation also contains codes that indicate the age, origin, and, where possible, composition. In order to interpret UNIT_ABBREV, it is necessary to be aware of the following:

1. Ages are indicated by uppercase letters and by lowercase letters and (or) numbers preceding them. The lowercase letters and numbers indicate subdivisions of time-stratigraphic units. Most of these follow standard conventions, but some are not obvious because geologic special characters were substituted for standard characters:

\begin{tabular}{|c|c|}
\hline CZ - Cenozoic & M - Mississippian \\
\hline Q - Quaternary & D - Devonian \\
\hline pQ - Pleistocene & S - Silurian \\
\hline $\mathrm{T}$ - Tertiary & O - Ordovician \\
\hline plT - Pliocene & CA - Cambrian \\
\hline nT - Neogene & pCA - Precambrian \\
\hline $\mathrm{mT}$ - Miocene & Z - Late Proterozoic (570-900 Ma) \\
\hline pgT - Paleogene & Y - Middle Proterozoic (900-1,600 Ma) \\
\hline oT - Oligocene & $\mathrm{Y}^{1}$ - Middle Proterozoic (1400-1,600 Ma) \\
\hline eT - Eocene & $\mathrm{Y}^{2}$ - Middle Proterozoic (1,200-1,400 Ma) \\
\hline paT - Paleocene & $\mathrm{Y}^{3}$ - Middle Proterozoic (900-1,200 Ma) \\
\hline MZ - Mesozoic & X - Early Proterozoic (1,600-2,500 Ma) \\
\hline K - Cretaceous & $\mathrm{X}^{1}$ - Early Proterozoic $(2,100-2,500 \mathrm{Ma})$ \\
\hline J - Jurassic & $\mathrm{X}^{2}$ - Early Proterozoic $(1,800-2,100 \mathrm{Ma})$ \\
\hline TR - Triassic & $\mathrm{X}^{3}$ - Early Proterozoic $(1,600-1,800 \mathrm{Ma})$ \\
\hline PZ - Paleozoic & A - Archean \\
\hline P - Permian & W - Late Archean \\
\hline
\end{tabular}

2. Major subdivisions of time-stratigraphic units are generally indicated by l (lower), m (middle), and u (upper). In plutonic rocks the same subdivisions indicate Early, Middle, and Late because the convention is to indicate geologic time 
rather than the rocks deposited during that time. Further subdivisions are indicated by numbers, starting with the oldest $=1$. In the Precambrian, superscripts are used for subdivisions, for example $\mathrm{Y}^{1}, \mathrm{Y}^{2}, \mathrm{Y}^{3}$. Combined units or units of uncertain age are indicated by double age designations, with the oldest age first. Where only an age designation appears in the unit label, the unit is sedimentary. In a few areas in the Canadian Shield and in the upper Midwest, the symbols Xcs and Xqz are used to identify units of Early Proterozoic sandstone and conglomerate, and quartzite, respectively.

a. For volcanic rocks, the age designation is followed by a lowercase "v" (for example, plTv - Pliocene volcanic rocks). Lowercase letters following the "v" indicate lithology: $\mathrm{f}$ - felsic; i - intermediate; $\mathrm{m}$ - mafic; sv - mixed sedimentary and volcanic; b - bimodal; k - alkalic (for example, plTvmk - Pliocene alkaline mafic volcanics).

b. For plutonic rocks, lowercase letters following the age designation indicate lithology: q - quartz monzonite and granite; g - undivided granitoid; $\mathrm{f}$ - felsite; $\mathrm{i}$ - granodiorite and quartz diorite; $\mathrm{m}$ - diorite and gabbro; $\mathrm{y}$ syenite and monzodiorite; my - alkaline gabbro and syenite; a - anorthosite; and $\mathrm{u}$ - ultramafic.

c. For high-grade metamorphic rocks, age of the protolith is given. Lowercase letters following the age designation indicate lithology of the protolith: $\mathrm{n}$ - gneiss; sn - sedimentary gneiss; gn - granitic gneiss; and sgn paragneiss and orthogneiss. Undivided crystalline rocks are indicated by $\mathrm{x}$.

d. Lower-case letters without age designations indicate lithology of units of unknown or unspecified age: u ultramafic rocks; $\mathrm{x}$ - crystalline rocks; and $\mathrm{g}$ - granitoid rocks.

e. Seafloor units are indicated by single asterisks $(*)$ following the unit abbreviation. Special seafloor units are indicated by two asterisks (**) following the unit abbreviation. Description of special seafloor units can be found in the MAP_UNIT_NOTE attribution field of the feature class.

f. Units with a query (?) before the unit abbreviation indicate uncertainty about age. Units with a query (?) after the unit abbreviation indicate uncertainty about composition or whether the rock is in situ. Unit uncertainty information can also be queried via the UNIT_UNCERTAINTY and AGE_UNCERTAINTY attribution field(s) of the feature class.

Phanerozoic rocks regionally metamorphosed to amphibolite facies or higher (or blueschist facies or higher in active orogenic belts) are distinguished by a diagonal line and are stored in the Geologic_overprints feature class, as are rocks metamorphosed to granulite facies in the Canadian shield. Other special lithologies and depositional environments such as melange, predominately continental deposits, and off-shelf (not offshore) marine deposits exposed on land are symbolized with dotted patterns.

\section{Acknowledgements}

The authors wish to thank the compilers of the source map (Jack Reed, U.S. Geological Survey; John Wheeler, Geological Survey of Canada; and Brian Tucholke, Woods Hole Oceanographic Institute) for their interpretations and additional information provided during the long process of converting the map to database. The Geological Society of America and U.S. Geological Survey cooperatively provided funding to create the Adobe Illustrator files from which the map was printed and from which this database was derived. The authors thank the GSA for enthusiastic endorsement of this project, to build a database from their highly significant map. 


\section{References Cited}

Asch, Kristine, 2003, The 1:5-million international geological map of Europe and adjacent areas—Development and implementation of a GIS-enabled concept: Geologisches Jahrbuch, Reihe A, Heft SA 3, 190 p., http://www.bgr.de/karten /IGME5000/igme5000.htm.

Garrity, C.P., and Soller, D.R., 2006, Prototype GIS Database for the DNAG geologic map of North America, in Soller, D.R., ed., Digital mapping techniques '06-Workshop proceedings: U.S. Geological Survey Open-File Report 2007-1285, p. 197-201, http://pubs.usgs.gov/of/2007/1285/pdf/Garrity.pdf.

Garrity, C.P., and Soller, D.R., in press, DNAG Geologic map of North America GIS implementation-Overview and progress, in Soller, D.R., ed., Digital mapping techniques '07—Workshop proceedings: U.S. Geological Survey Open-File Report 2008-1385.

Reed, J.C., Jr., Wheeler, J.O., and Tucholke, J.E., comps., 2005a, Geologic map of North America: Boulder, Colo., Geological Society of America, Decade of North American Geology Continental Scale Map 001, scale 1:5,000,000, http://rock.geosociety.org/bookstore/default.asp?oID= 0\&catID=2\&pID=CSM001F.

Reed, J.C., Jr., Wheeler, J.O., and Tucholke, B.E., 2005b, Geologic map of North America-Perspectives and explanation: Boulder, Colo., Geological Society of America, Decade of North American Geology, 28 p.

Snyder, J.P., 1987, Map projections—A working manual: U.S. Geological Survey Professional Paper 1395, 383 p.

Soller, D.R., 2005, Digital database, in Reed, J.C., Jr., Wheeler, J.O., and Tucholke, B.E., Geologic map of North AmericaPerspectives and explanation: Boulder, Colo., Geological Society of America, Decade of North American Geology, p. 20. 